\title{
Four novel and three recurrent mutations of the BTK gene and pathogenic effects of putative splice mutations
}

\author{
Duangrurdee Wattanasirichaigoon · Suwat Benjaponpitak · \\ Chonnamet Techasaensiri - Wasu Kamchaisatian - Pakit Vichyanond · \\ Sucheela Janwityanujit · Lulin Choubtum · Sayomporn Sirinavin
}

Received: 3 July 2006/ Accepted: 7 August 2006/Published online: 2 September 2006

(C) The Japan Society of Human Genetics and Springer 2006

\begin{abstract}
X-linked agammaglobulinemia is caused by mutations in the human $B T K$ gene, leading to recurrent pyogenic infections. We describe four novel and three known $B T K$-mutations in seven patients from seven (six Thai and one Burmese) families. All but one were sporadic cases. Patients 1 and 2 had recurrent mutations in exon 10 (R288W) and exon 17 (R562W), respectively. Patient 3, a previously healthy individual who presented with pseudomonas sepsis with ecthyma gangrenosum had a known mutation in exon 17 (1749delT), leading to frameshift effect (F583fsX586). Patient 4 manifested with sepsis and concurrent acute appendicitis and pneumonia. $\mathrm{He}$
\end{abstract}

Electronic supplementary material Supplementary material is available in the online version of this article at http://dx.doi.org/ $10.1007 / \mathrm{s} 10038-006-0052-\mathrm{y}$ and is accessible for authorized users.

D. Wattanasirichaigoon $(\square) \cdot S$. Benjaponpitak ·

C. Techasaensiri - W. Kamchaisatian · S. Sirinavin

Department of Pediatrics, Faculty of Medicine,

Ramathibodi Hospital, Mahidol University,

Rama VI Road, Bangkok 10400, Thailand

e-mail:radwc@mahidol.ac.th

P. Vichyanond

Department of Pediatrics, Faculty of Medicine,

Siriraj Hospital, Mahidol University,

Bangkok, Thailand

S. Janwityanujit

Department of Medicine, Faculty of Medicine,

Ramathibodi Hospital, Mahidol University,

Bangkok, Thailand

L. Choubtum

Research Center, Faculty of Medicine,

Ramathibodi Hospital, Mahidol University,

Bangkok, Thailand had a mutation, IVS $8+1 \mathrm{G}>\mathrm{A}$, which led to an insertion of intron 8 into the transcripts. In Patient 5, a novel change in exon 7 , c.588G $>\mathrm{C}$, initially presumed Q196H, was found to cause a leaky splicing mutation, resulting in three distinct transcripts containing 17, 108, and $190 \mathrm{bp}$ of the $5^{\prime}$-terminal of intron 7, which led to truncated peptides consisting of 203 and 211 amino acid residues (or Q196fsX204 and Q196fsX212, respectively). Patient 6 had a mutation in exon 14 (W421X), while patient 7 had a newly defined large deletion of exons 6-9. All of the mothers tested were mutation carriers. Transcript analysis in three mothers who were heterozygous for frameshift mutations revealed a minimal amount of aberrant transcripts, while their affected children had full expression of the mutant alleles, suggesting rapid degradation due to nonsense-mediated mRNA decay in the mothers. This is the first report of mutations of $B T K$ from Thailand.

Keywords $B T K$ gene $\cdot$ Ecthyma gangrenosum · Splice mutation $\cdot$ XLA

\section{Introduction}

X-linked agammaglobulinemia (XLA) or Bruton hypogammaglobulinemia (OMIM 300300) is characterized by recurrent bacterial infections in affected hemizygous males in the first two years of life. Recurrent otitis, sinopulmonary infections, conjunctivitis, diarrhea, and skin infections are common manifestations. Individuals with XLA fail to make antibodies to vaccine and bacterial antigens. In addition, chronic inflammatory disorders, such as arthritis, inflammatory 
bowel disease, or allergy-like symptoms, have been found to be present in $20 \%$ of all XLA patients (Conley et al. 2005).

The serum immunoglobulin $(\mathrm{Ig}) \mathrm{G}$ level in XLA patients is typically less than $200 \mathrm{mg} / \mathrm{dl}$, with approximately only $10 \%$ having $\mathrm{IgG}$ levels $>200 \mathrm{mg} / \mathrm{dl}$; the serum levels of IgM and IgA are generally less than $20 \mathrm{mg} / \mathrm{dl}$ (Conley and Howard 2002; Conley et al. 2005). Most patients are recognized as having immune deficiency before 5 years of age (Conley et al. 2005), with only about $10 \%$ of all XLA individuals not being diagnosed until after 10 years of age owing to higher serum immunoglobulin concentrations than expected. The most consistent feature in XLA patients is markedly reduced numbers of B-lymphocytes (CD19+ cells) in the peripheral circulation $(<1 \%$ ) (Conley and Howard 2002; Conley et al. 2005).

The disease is caused by mutations in the human Bruton's tyrosine kinase $(B T K)$ gene, which is located on Xq22.1-q22.2. This gene contains 19 exons with uncoding exon 1 , and spreads over $37 \mathrm{~kb}$ of DNA (Hagemann et al. 1994). The normal peptide consists of 659 amino acid residues (Hagemann et al. 1994). BTK belongs to a group of related cytoplasmic phosphotyrosine kinases formed by the TEC family of proteins. These proteins are characterized by five distinct structural domains, including a splecktrin homology domain $(\mathrm{PH})$, Tec homology domain $(\mathrm{TH})$, two protein interaction domains ( $\mathrm{SH} 2$ and $\mathrm{SH} 3)$, and a catalytic or kinase domain (SH1) (Hagemann et al. 1994). Mutations of $B T K$ are scattered throughout the gene, and most are family-specific [The Human Gene Mutation Database (HGMD), available at http:// www.hgmd.org/]. In the investigation reported here, the authors carried out mutational analysis in a group of seven XLA patients.

\section{Patients, materials, and methods}

Patients with a clinically confirmed diagnosis of XLA were enrolled in the study. Medical records were reviewed. Blood was taken for genetic analysis after informed consent was given, following approval by the Institutional Review Board.

Genomic DNA was isolated from peripheral blood following an established protocol. Each exon was amplified and sequenced with intron-flanking primers (program PRIMER 3 was used for primer design; http:// www.Frodo.wi.mit.edu/cgi-bin/primer3/primer3_www. cgi). The PCR conditions consisted of 35 cycles at $94^{\circ} \mathrm{C}$ for $1 \mathrm{~min}, 60-62^{\circ} \mathrm{C}$ for $1 \mathrm{~min}$, and $72^{\circ} \mathrm{C}$ for $1 \mathrm{~min}$. Whenever a deletion of exon(s) was suspected based on absent PCR amplicons, a multiplex PCR was performed for confirmation. To identify the source of the mutation, mothers and maternal grandmothers were encouraged to participate in the study. PCRrestriction digest analyses were performed as a second method to confirm a newly identified mutation and also to screen for the mutation in family members and 50 healthy controls.

mRNA (cDNA) was analyzed in order to evaluate the effect of putative splicing and frameshift mutations. For the RNA isolations, lymphocytes were isolated from peripheral blood by Ficoll-Paque PLUS density centrifugation (Amersham Biosciences, Sweden), and total RNA was extracted with Trizol LS reagent (Life Technologies, Egenstein, Germany), then reversetranscribed into complementary DNA (cDNA) using the SuperScript III First-Strand Synthesis Supermix for RT-PCR (Invitrogen, Carlsbad, Calif.). PCR amplicons were sequenced on an ABI 3100 DNA Sequencher (Applied BioSystems, Foster City, Calif.) and/or sent for sequencing at MACROGEN (Macrogen, Seoul, Korea). Primers for cDNA amplification and sequencing are as follows:

- E5-6 (forward) 5'-CGTAATCCGGTACAACA GTG-3' and E10-11 (reverse) 5'-CTTTCCCCTC TTGCTTTAGC-3' for the c.588G > C analysis;

- E7-8 (forward) 5'-GGACCAGATCTTGAAAA AGC-3' and E12 (reverse) 5'-TAATGACGTATC ACCCCTTG-3' for the IVS8 + $1 \mathrm{G}>\mathrm{A}$ analysis;

- E16 (forward) 5'-GCAGCTCGAAACTGTTTG GT-3' and E18 (reverse) 5'-TACCTTCTCTGAA GCCAGATG-3' for the c.1747delT analysis.

To determine the X-inactivation pattern in the mothers who were heterozygous for the protein truncation mutation (1749delT, IVS $8+1 \mathrm{G}>\mathrm{A}$, and c. $588 \mathrm{G}>\mathrm{C}$ ) and shown to have null or minimal amount of the mutant transcripts, methylation-specific PCR (MSP) was performed following previously published protocols with some modifications (Kubota et al. 1999; Nakayama et al. 2000; Weinhausel and Haas 2001). The assays included two steps: bisulfite treatment followed by PCR amplification with primers specific to either methylated or unmethylated DNA. Briefly, genomic DNA $(1.2 \mu \mathrm{g})$ was denatured in $0.3 \mathrm{M}$ $\mathrm{NaOH}$ at $95^{\circ} \mathrm{C}$ for $6 \mathrm{~min}$. The specimen was then treated with sodium bisulfite in a final concentration of 2.6 $M$ and with hydroquinone in a final concentration of $0.5 \mathrm{mM}$, and the reaction was allowed to proceed at $55^{\circ} \mathrm{C}$ for $4 \mathrm{~h}$, at which time the solution was desalted using the Wizard DNA Purification kit (Promega, Madison, Wis.) according to the manufacturer's instructions. The bisulfite modification was completed 
by $0.3 \mathrm{M} \mathrm{NaOH}$ treatment at $37^{\circ} \mathrm{C}$ for $10 \mathrm{~min}$ followed by $10 M$ ammonium acetate and ethanol precipitation (Nakayama et al. 2000).

Ten primers were used for amplifying the promoter sequence of the fragile $\mathrm{X}$-mental retardation (FMR1) and $\mathrm{X}$-inactivation-specific transcript (XIST) genes, the trinucleotide CGG repeat segments of FMR1, and the CAG repeat segment of human androgen receptor $(A R)$ genes. The $X I S T$ promoter served as an internal control. The XIST gene promoter is methylated on the active $\mathrm{X}$ chromosome, therefore the allelic methylation pattern opposes that of the FMR1 promoter (Weinhausel and Haas 2001). Polymorphism of the trinucleotide repeats was intended for use in the determination of percentage methylation for each site. Because about $50 \%$ of Thai female controls were found to be homozygous at the FMRI-CGG repeat segment, thereby giving a high chance of non-informative data, amplification of the repeat segment of $A R$ gene was additionally performed in order to increase the chance of a successful analysis (C. Limwongse, unpublished data). PCR products were separated on a $3.0 \%$ TBE agarose gel and visualized under UV illumination, followed by densitometric image analysis using the Gene Tools Analysis Software (ver. 3.02.00) package (Syngene, Cambridge, UK). The primer sequences and PCR conditions for BTK gene analysis and MSP are given as electronic supplementary materials - EMS_S1 and EMS_S2, respectively) which can be downloaded from the journal's website

\section{Results}

Seven unrelated male patients - six of Thai and one of Burmese descent - were enrolled in the study. Six cases were sporadic. Clinical presentation, immunologic profiles, and causative organisms are detailed in Table 1 . In all patients but one, the age of onset was after 2 years, and the diagnosis was made before 10 years. Two cases had uncommon manifestations, namely, acute appendicitis concurring with pneumonia, and sepsis and echtyma gangrenosum, both occurring in a previously healthy individual (Table 1). Pseudomonas aeruginosa was the most common causative organism. Two cases (Patients 3 and 4) had no history of recurrent/chronic sinopulmonary infections. None had a history of vaccine-associated polio following vaccination with liveattenuated oral polio vaccine. All had normal numbers of T-cells (data not shown), a normal CD4/CD8 ratio (range: 0.9-2.16), normal absolute neutrophil counts, and a negative anti-HIV antibody reading. In the majority of cases, IgG levels were, as expected, lower than $200 \mathrm{mg} / \mathrm{dl}$, with the exception of Patient 1 in whom the level was mildly low with decreased levels of $\mathrm{Ig}$ subclass G2 (45.8 mg/dl; normal range: $150-640)$ and G4 $(3.8 \mathrm{mg} / \mathrm{dl}$; normal range: $8-140)$.

Four novel (IVS8 + 1G > A, c.588G > C, W421X, and exons 6-9 deletion) and three recurrent (R288W, $\mathrm{R} 562 \mathrm{~W}$, and 1749delT) mutations were identified (Table 2). All of the mothers tested were mutation carriers, although only one of two maternal grandmothers tested was shown to be a mutation carrier. These mutations were not found in 50 controls (regular blood donors). The 1749delT mutation resulted in a frameshift effect without disruption of natural splicing and led to the premature truncation of the protein with a resultant 585aa-BTK peptide. The mutant allele was detected at both the genomic and mRNA levels in Patient 3, but only wild-type transcripts were present in the genomically confirmed heterozygous mother (Fig. 1a). The IVS $8+1 \mathrm{G}>$ A mutation disrupted the natural donor splice site, resulting in an aberrant mRNA transcript and a truncated peptide consisting of 259aa (Fig. 1b). The c.588G > C mutation at the last base of exon 7 destroyed its splice donor site and led to the activation of the cryptic splice donor site in intron 7 , resulting in three types of transcripts with insertions of 17, 108, and $190 \mathrm{bp}$ of the $5^{\prime}$-terminal of intron 7 (Fig. 1c). The aberrant transcript with the 17-bp segment produced a peptide of 203aa, while the other two produced a peptide of 211aa (Fig. 2). The result of X-inactivation analysis indicated random inactivation of the normal:1749delT allele (55:45), and noninformative results on the IVS $8+1 \mathrm{G}>\mathrm{A}$ and c. $588 \mathrm{G}>\mathrm{C}$ mutations due to homozygosity at the $F M R 1$ and $A R$ loci (Fig. 3). It is interesting to mention that the percentage of CD19 cells detected in the peripheral lymphocytes of Patient 5 was $2 \%$. A possible explanation is that these $\mathrm{B}$ cells have a wild-type BTK transcript because the BTK gene mutation of this patient is in the splice site; however, we were unable to detect the wild-type transcript in specimens obtained from this patient (Figs. 1c, 2b). A large deletion extending from exon 6 to 9 was identified in Patient 7 (Fig. 1d); mRNA was not available for analysis. This deletion is predicted to result in an mRNA transcript with the exon 5 sequence connected to exon 10 , resulting in a very short BTK protein consisting of 137 amino acids.

\section{Discussion}

$P$. aeruginosa was the most important infective organism identified in the present study. Possible 


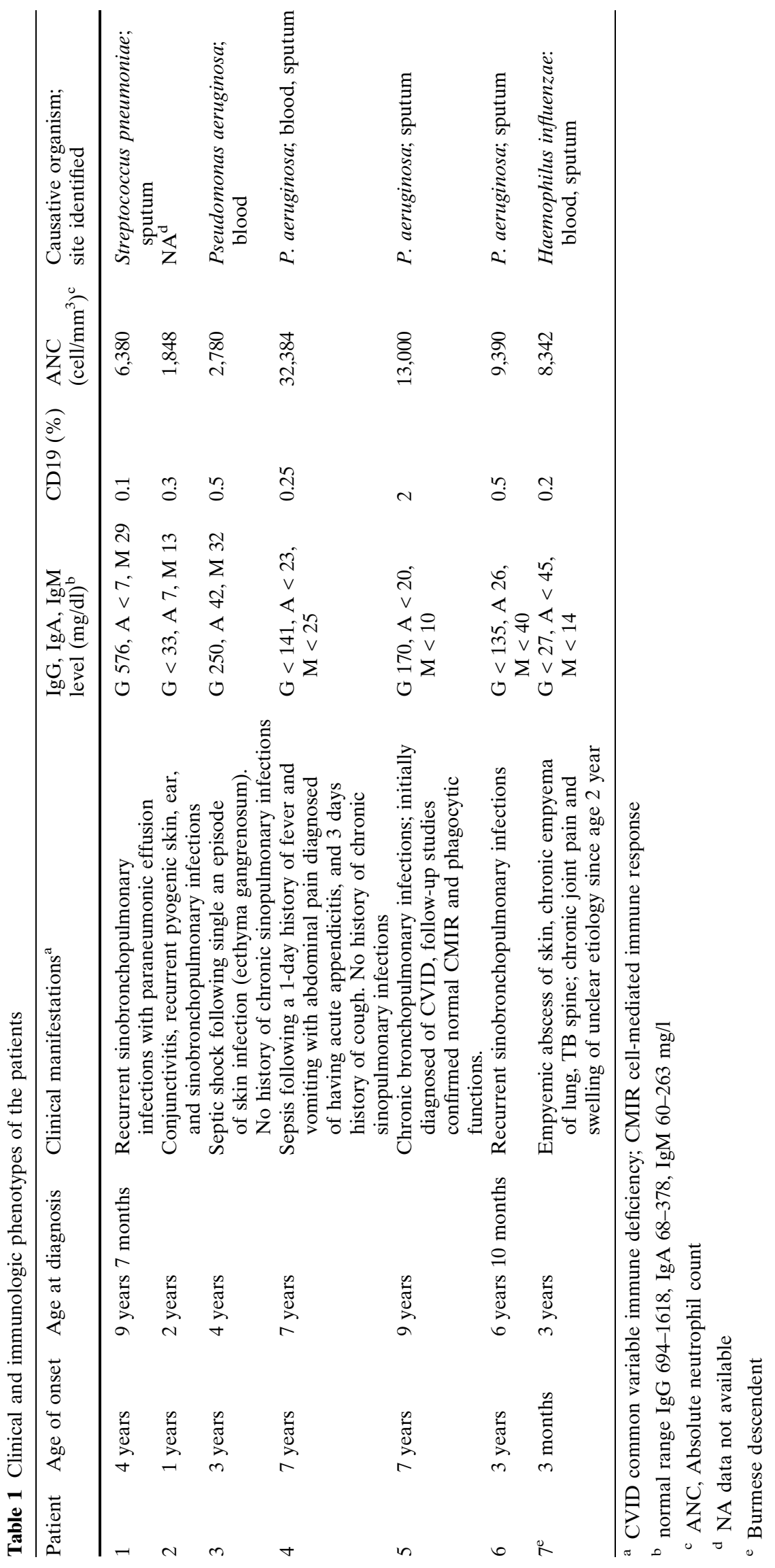


Table $2 B T K$ mutations identified and the consequences of these mutations. The gene nomenclature follows the recommendations of den Nunnen and Antonarakis [Hum Genet 109:121-124 (2001)]

\begin{tabular}{|c|c|c|c|c|c|c|c|c|}
\hline Patient & Exon & Nucleotide change $^{a}$ & $\begin{array}{l}\text { Consequence } \\
\text { of the mutation }\end{array}$ & Domain $^{b}$ & $\begin{array}{l}\text { Restriction } \\
\text { enzyme }\end{array}$ & $\begin{array}{l}\text { Family } \\
\text { history }\end{array}$ & $\begin{array}{l}\text { Carrier } \\
\text { status }^{\mathrm{c}}\end{array}$ & Reference $^{\mathrm{d}}$ \\
\hline 1 & 10 & c.862, $\mathbf{C G G}>$ TGG & R288W & $\mathrm{SH} 2$ & & No & Mother+ & HGMD \\
\hline 2 & 17 & c.1684, CGG > TGG & R562W & SH1 & & No & $\begin{array}{l}\text { MGM- } \\
\text { Mother+ } \\
2 \text { Sisters+ } \\
1 \text { Sister- }\end{array}$ & HGMD \\
\hline 3 & 17 & c.1749, 1749delT & F583fsX586 & SH1 & & No & Mother+ & HGMD \\
\hline 4 & Intron 8 & IVS8 + $1 \mathbf{G}>\mathbf{A}$ & G259fsX260 & SH3 & $H p h \mathrm{I}^{\mathrm{f}}$ & Yes & $\begin{array}{l}\text { MGM+ } \\
\text { Mother+ }\end{array}$ & Present study \\
\hline 5 & 7 & c. $588, \mathrm{CA} \mathbf{G}>\mathrm{CAC}$ & Q196fsX204, Q196fsX212 & $\mathrm{TH}$ & $B s a A \mathrm{I}^{\mathrm{g}}$ & No & Mother+ & Present study \\
\hline 6 & 14 & c. 1263, TGG > TGA & W421X & SH1 & $M b o \mathrm{II}^{\mathrm{g}}$ & No & Mother+ & Present study \\
\hline $7^{e}$ & $6,7,8,9$ & Deletion of exons 6-9 & V131fsX137 & $\mathrm{PH}$ & & No & NA & Present study \\
\hline
\end{tabular}

${ }^{a}$ Genbank reference sequences, NT_011651 and NP_000052.1

b PH, Pleckstrin homology domain; TH, Tec homology domain; SH1, SH2, and SH3, Src homology 1, 2, and 3 in the respective order

c MGM, Maternal grandmother; NA, not available for testing; +, positive for the mutation; -, negative for the mutation

d HGMD, The Human Gene Mutation Database, http://www.hgmd.org/

e Burmese descendant

${ }^{\mathrm{f}}$ The mutation abolishes the restriction site

g The mutation creates a new restriction site

explanations for this are a delayed diagnosis, the prolonged use of antibiotics, mild-to-moderate spectrum of the disease, under-recognition of the disease until the onset of severe infection, and increased susceptibility to pseudomonas infection due to an as yet unknown mechanism(s) (Baro et al. 2004; Zenone and Souillet 1996). It has been proposed that preceding viral infection precipitating neutropenia leads to pseudomonas and staphylococcal infections in XLA patients (Conley et al. 2005). This may not be the only influencing factor as some XLA patients develop infections without such antecedence, as seen in Patient 3. The initial common variable immune deficiency (CVID)-like features in Patient 5 suggest that BTKmutation screening should be performed in all CVIDlike cases, especially in male patients, until there is better understanding of the gene(s) defect underlying CVID (Conley et al. 2005; Lin et al. 2006; Ohta et al. 1994).

The mutations that we identified in this study were spread throughout the gene. The R288W mutation has been reported multiple times in various populations, including Swedish, Spanish, Italian, North American, Australian, and Chinese, perhaps representing a mutational hotspot or an ancient mutation (Conley et al. 2005; Fiorini et al. 2004; Lopez-Granados et al. 2005; Rodriguez et al. 2001; Tzeng et al. 2000; Velickovic et al. 2004; Vorechovsky et al. 1995). It results in normal protein expression and kinase activity, but an impaired phosphotyrosine-binding capacity which is the main function of the $\mathrm{SH} 2$ domain (Perez de Diego et al. 2005; Vihinen et al. 1994). Of note, three of the four R288W-patients (including Patient 1) whose immunological data were available had relatively high levels of IgG (range: $220-575 \mathrm{mg} / \mathrm{dl}$ ); all had clinically severe disease. The R562W mutation, which is a non-conservative change from a positively charged arginine residue to a nonpolar tryptophan residue in the kinase (SH1) domain, is predicted to interfere with the autophosphorylation capacity (Vorechovsky et al. 1995). In family 2 , the absence of R562W in the maternal grandmother despite the presence of the mutation in the mother suggests that the mutation might have occurred de novo during spermatogenesis or oogenesis in either of her parents, then passed to the mother and later to her affected offspring.

The 1749delT mutation, although located close to the splice donor site of intron 17, did not interfere with natural splicing but had instead a frameshift effect leading to a premature stop codon with a resultant 585aa-BTK peptide. The pathogenic effect of IVS8 $+1 \mathrm{G}>\mathrm{A}$ is missplicing, leading to an aberrant transcript containing the whole intron 8 sequence and a truncated peptide consisting of 259aa (G259fsX260). The c.588G > C mutation, which is caused a leaky splicing error, results in two species of abnormally short BTK peptides: the first (or Q196fsX204) consists of 203 amino acid residues produced by the transcript containing the first $17 \mathrm{bp}$ of intron 7; the second (or Q196fsX212) consists of 211 amino acid residues 


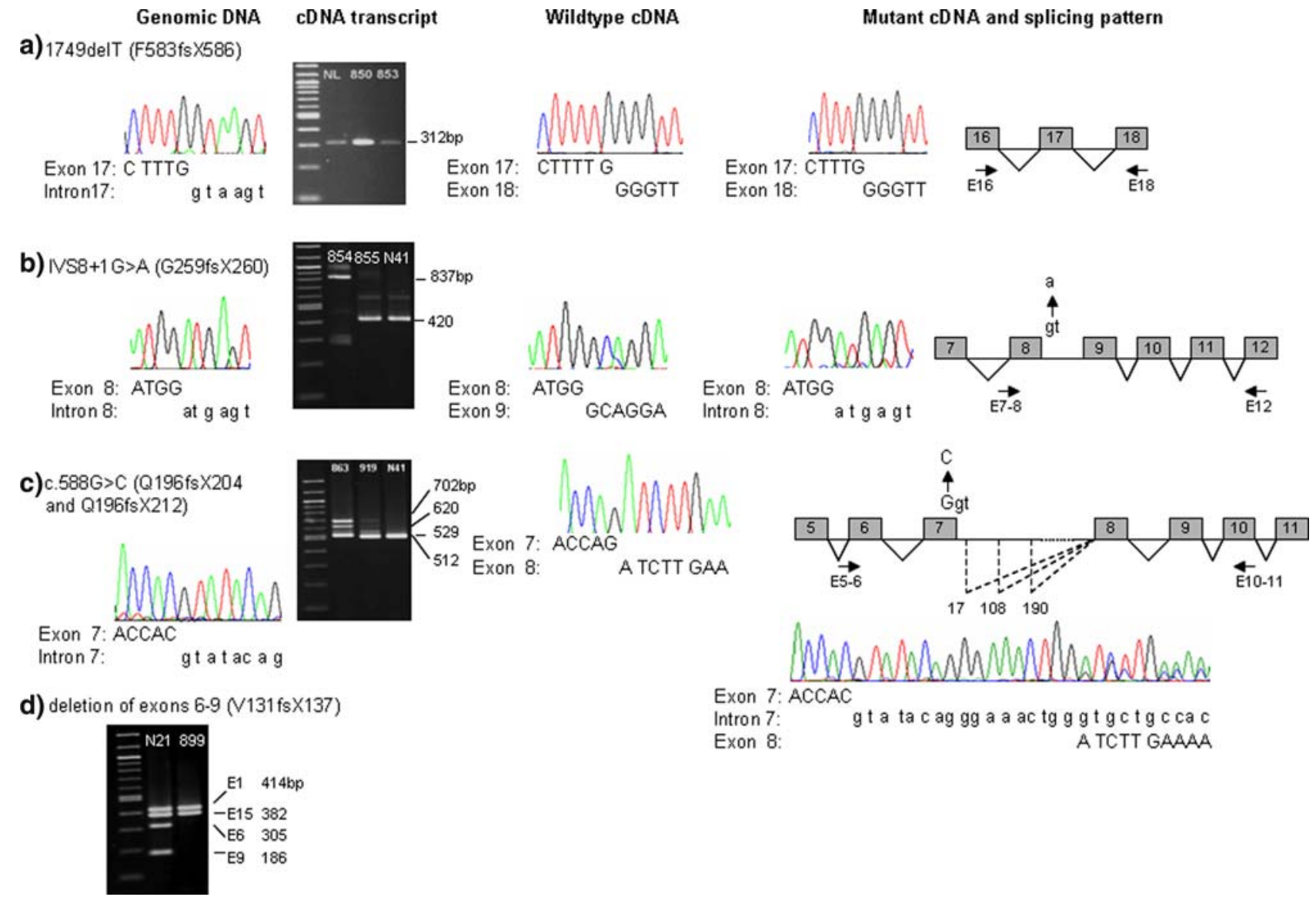

Fig. 1 Genomic DNA and transcript analysis of frameshift mutations. a 1749delT; note a $\mathrm{T}$ deletion near the end of exon 17, with only a single band (around $312 \mathrm{bp}$ ) of the transcripts visualized in normal individual $(N L)$, Patient 4 (853), and the mother (850). Mutant cDNA yields a T deletion without splicing error. b IVS $8+1 \mathrm{G}>\mathrm{A}$; this mutation illustrates the G-to-A replacement at the first base of intron 8 leading to splicing error. The mother (855) and normal control (N41) showed the wild-type 420-bp transcript; Patient 5's (854) mutant transcript was 837 bp in length, with 417 bp of the IVS 8 fragment in addition to the wild-type cDNA sequence. The mutant cDNA sequence reveals the insertion of intron 8 before joining exon 9. c c.588G > C; note the G-to-C substitution at the last base of exon 7. Note the 512-bp wild-type transcript (N41), three distinct aberrant transcripts in Patient 6's RNA (863), the bottom 529-bp band containing 17 bp of the $5^{\prime}$-terminal of intron 7 , the middle 620-bp band containing the 108-bp 5'-terminal of intron 7, and the upper top 702-bp band containing $190 \mathrm{bp}$ of the 5 -terminal of intron 7. The mother's RNA (919) revealed a small amount (faint bands) of aberrant transcripts. Mutant cDNA showed a mixture of aberrant sequences, the 529-bp transcript having only the first $17 \mathrm{bp}$ of intron 7 then followed by the exon 8 sequence, while the 620-bp transcript contains the $108 \mathrm{bp}$ of the intron 7 sequence before joining exon 8 . Sequenogram of the 702-bp transcript is not shown. The complete length of intron 7 is $1417 \mathrm{bp}$. Schematic diagram of the $B T K$ gene illustrating aberrant splicing patterns with activation of cryptic splice donor site at 17, 108, and $190 \mathrm{bp}$ downstream from the IVS7-natural splice donor site (dashed line). Arrows shown below the diagrams indicate the approximate locations of the PCR primers used in the reverse transcriptase-PCR analysis. A 100-bp DNA ladder (New England BioLabs, Beverly, Mass.) was used as a size marker

IVS $8+1 \mathrm{G}>\mathrm{A}$ and c.588G $>\mathrm{C}$ mutations in the heterozygous mothers suggest that the mutant transcripts were perhaps highly unstable due to nonsense-mediated mRNA decay, which is a mechanism of preventing the synthesis of truncated and potentially harmful proteins (Conti and Izaurralde 2005). Nonrandom X-inactivation was excluded based on the normal $\mathrm{X}$-inactivation profiles in the 1749delT case. Conversely, in the hemizygous males (Patients 3, 4, and 5) the mutant allele was the single allele present; full expression despite aberrant
The absence of the 1749delT transcript and the trivial amount of the transcripts derived from the 


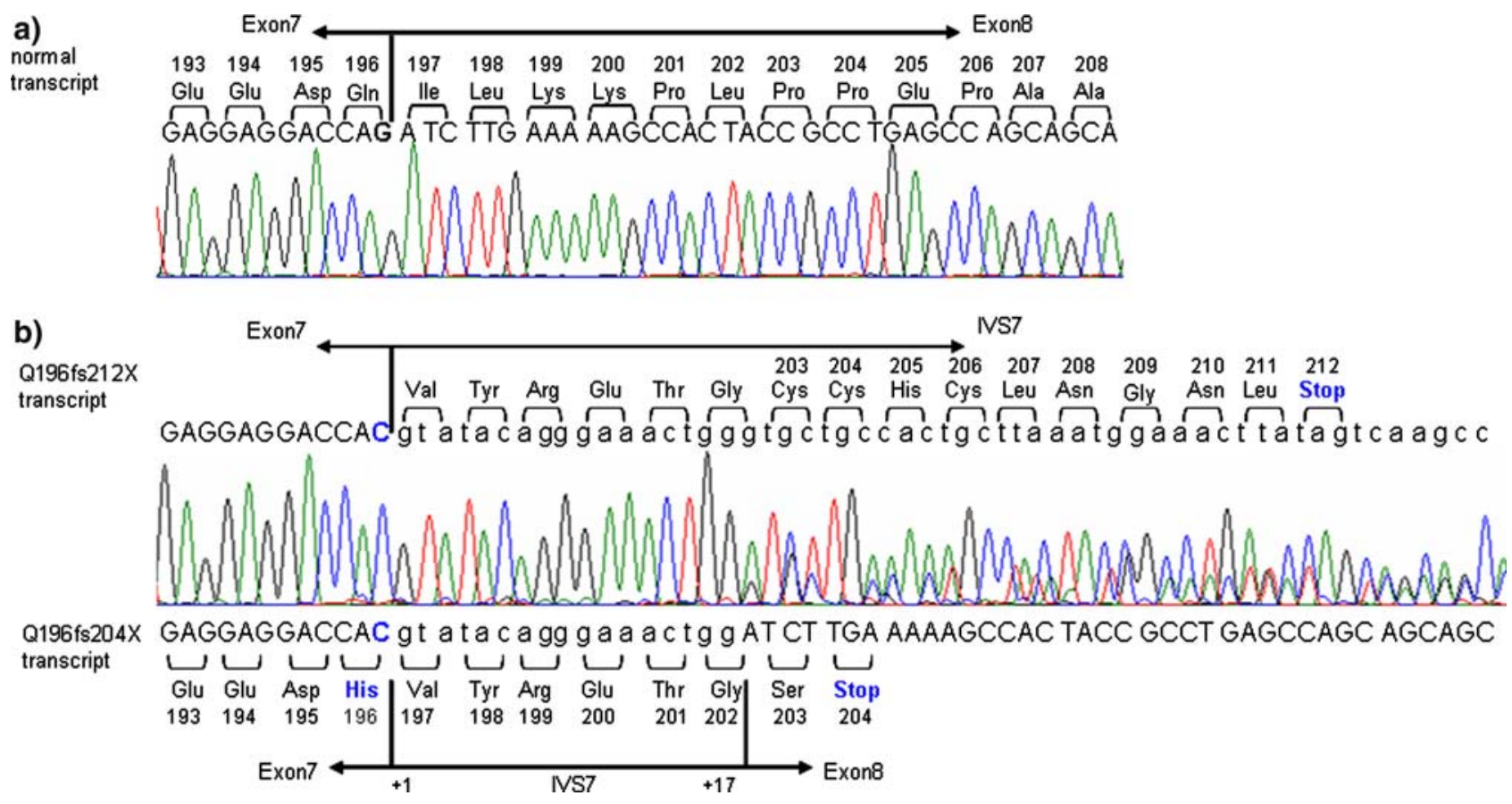

Fig. 2 Sequenogram of the BTK transcript and predicted resultant peptides. a normal, b mutant transcripts derived from the c.588G > C mutant allele, resulting in Q196fsX204 and Q196fxX212

a)

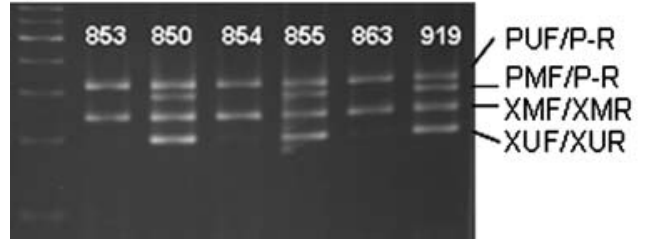

b)

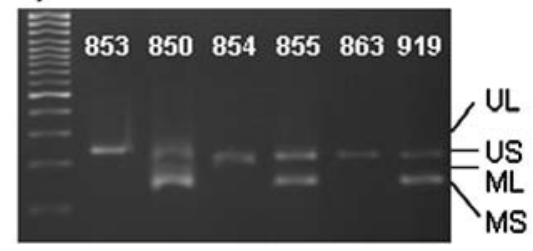

c)

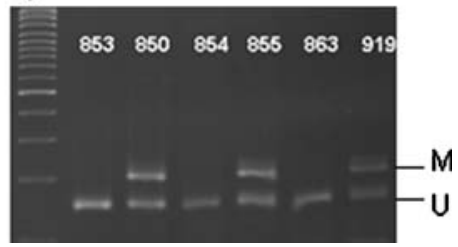

Fig. 3 X-inactivation and methylation-specific PCR (MSP) analyses. a Promoter PCR products. Note bands: $P U F / P-R$ (318 bp) products of unmethylated fragile $\mathrm{X}$ mental retardation1 (FMR1) promoter, $P M F / P-R$ (288 bp) methylated FMR1 promotor, $X M F / X M R$ (241 bp) methylated X-inactivation-specific transcript (XIST) promoter, XUF/XUR (198 bp) unmethylated XIST promoter. Since the XIST promoter is methylated on the active $\mathrm{X}$ chromosome, note allelic methylation pattern opposite to that of the FMR1 promoter. The patients $(853,854$, and 863) were shown to have unmethylated FMR1 and methylated XIST promoters. Their mothers $(850,855$, and 919), all with two X chromosomes, show both unmethylated and methylated alleles for FMRI and XIST promoters. The intensity of the upper two bands (FMR1 promotor) should be equal, as should that of the lower two bands (XIST promoter). The intensity of the bands of either of the FMR1 or XIST pair can be measured and used as a standard intensity. In our case, the XIST pair was chosen and the intensity of each band (XMF/ $\mathrm{XMR}$ and XUF/XUR) was measured to be equal and designated as 50:50. b Polymorphic and percentage methylation analysis of the repeat segment at the androgen receptor $(A R)$ locus. Note that the mother (850: 1749delT carrier) of Patient 3 had four bands - $U L$ unmethylated larger allele, $U S$ unmethylated smaller allele, $M L$ methylated larger allele, $M S$ methylated smaller allele - indicating heterozygosity at the repeat site, which suggested that percentage methylation analysis would be informative.
Patient 3 (853) inherited an $\mathrm{X}$ chromosome consisting of the larger repeat allele $(U L)$ of the $A R$ locus. The intensity of the four bands in the mothers (850) was measured as follows: UL, 22.43; US, 28.59; ML, 33.03; MS, 62.19 (relative intensity compared to $\mathrm{XMF} / \mathrm{XMR}$ and $\mathrm{XUF} / \mathrm{XUR}$ ). The formula $\mathrm{MS} / \mathrm{ML}=\mathrm{UL} / \mathrm{ML} \sqrt{\mathrm{ML} \times \mathrm{MS} / \mathrm{UL} \times \mathrm{US}}$, as previously described (Kubota et al. 1999), was applied to the data set, revealing the MS/ML ratio to be 55:45 and thereby suggesting random X-inactivation in the mother. Ideally, the intensity ratio of the smaller $(M S)$ and longer methylated $(M L)$ repeat alleles should be about 50:50. The intensity ratio $>80: 20$ or $<20: 80$ is considered nonrandom X-inactivation (Kubota et al. 1999). The other two patients (854 and 863) and their mothers (855: IVS8 + 1G > A carrier; 919: c.588G > C carrier) revealed only smaller alleles, suggesting homozygosity and a non-informative allele at this site. The size of the unmethylated allele was $153+3 n \mathrm{bp}$, and that of the methylated allele was $90+3 n$ bp, where $n$ is the numbers of CAG repeats. c Repeat segment at the $F M R 1$ locus. Note the single unmethylated allele $(U)$ and single methylated allele $(M)$ in the mothers $(850,855$, and 919$)$ of the three patients $(853,854$, and 863$)$, suggesting homozygosity at this site and noninformative alleles for percentage methylation analysis. The size of unmethylated allele was $64+3 n$ bp, and that of the methylated allele was $120+3 n$ bp, when $n$ is the number of CGG repeats 
function was perhaps unavoidable. Silence or a marked reduction at the mRNA level of the mutant allele in a heterozygote of the protein truncation mutation has been observed in a carrier for protein S deficiency (an autosomal recessive disorder) in which the heterozygous father was found to have only normal mRNA while his affected child expressed two species of mutant mRNA, one of each inherited from his parents (Yamazaki et al. 1997). Although mRNA analysis represents a good alternative to genetic diagnosis, the application of mRNA-based analysis for carrier detection of an $\mathrm{X}$-linked recessive disorder in female relatives should be practiced with caution as it may lead to false diagnosis owing to possible silencing of the mutated allele.

Gross deletions account for $3-8 \%$ of the $B T K$ mutations reported (http://www.hgmd.org/). The deletion of exons 6-9 is predicted to result in a very short BTK protein consisting of 137 amino acids and, most likely, a severe and early onset of infection. Patient 7 carrying this mutation, lived in an endemic area of tuberculosis and suffered tuberculous infection of spine, which is not a common finding in XLA patients, suggesting that a specific mutation in $B T K$ may not be the only factor modulating the severity of the disease and that environmental conditions and genetic variants of other immune-related genes may also play a role (Conley and Howard 2002; Conley et al. 2005).

In summary, our data demonstrate an expanded clinical and mutational spectrum of XLA. This result supports previous evidence that mutations are scattered throughout the gene. mRNA analysis is important for obtaining a full understanding of the putative splicing mutations of the BTK gene. The presence of mutations in all of the mothers of the sporadic patients addresses the necessity of carrier detection for the purpose of genetic counseling and prenatal diagnosis, particularly in a country with limited resources for lifelong expensive treatment and a high prevalence of infections with virulent organisms.

Acknowledgments This work was support by grants from Mahidol University. We are grateful to Drs. Wiparat Manuyakorn and Patrin Jaovisidh for referring the patients, Drs. Chanin Limwongse and Suttikarn Pongtepaditep for technical assistance, Dr. Pim Suwannarat for editing the manuscript, and to the Faculty of Medicine, Ramathibodi Hospital for its funding for Research Career Development to D.W.

\section{References}

Baro M, Marin MA, Ruiz-Contreras J, de Miguel SF, SanchezDiaz I (2004) Pseudomonas aeruginosa sepsis and ecthyma gangrenosum as initial manifestations of primary immunodeficiency. Eur J Pediatr 163:173-174
Conley ME, Broides A, Hernandez-Trujillo V, Howard V, Kanegane H, Miyawaki T, Shurtleff SA (2005) Genetic analysis of patients with defects in early B-cell development. Immunol Rev 203:216-234

Conley ME, Howard V (2002) Clinical findings leading to the diagnosis of $\mathrm{X}$-linked agammaglobulinemia. J Pediatr 141:566-571

Conti E, Izaurralde E (2005) Nonsense-mediated mRNA decay: molecular insights and mechanistic variations across species. Curr Opin Cell Biol 17:316-325

Fiorini M, Franceschini R, Soresina A, Schumacher RF, Ugazio AG, Rossi P, Plebani A, Notarangelo LD (2004) BTK: 22 novel and 25 recurrent mutations in European patients with X-linked agammaglobulinemia. Hum Mutat 23:286

Hagemann TL, Chen Y, Rosen FS, Kwan SP (1994) Genomic organization of the Btk gene and exon scanning for mutations in patients with $\mathrm{X}$-linked agammaglobulinemia. Hum Mol Genet 3:1743-1749

Hashimoto S, Tsukada S, Matsushita M, Miyawaki T, Niida Y, Yachie A, Kobayashi S, Iwata T, Hayakawa H, Matsuoka H, Tsuge I, Yamadori T, Kunikata T, Arai S, Yoshizaki K, Taniguchi N, Kishimoto T (1996) Identification of Bruton's tyrosine kinase (Btk) gene mutations and characterization of the derived proteins in $35 \mathrm{X}$-linked agammaglobulinemia families: a nationwide study of Btk deficiency in Japan. Blood 88:561-573

Kaneko H, Kawamoto N, Asano T, Mabuchi Y, Horikoshi H, Teramoto T, Matsui E, Kondo M, Fukao T, Kasahara K, Kondo N (2005) Leaky phenotype of X-linked agammaglobulinaemia in a Japanese family. Clin Exp Immunol 140:520-523

Kubota T, Nonoyama S, Tonoki H, Masuno M, Imaizumi K, Kojima M, Wakui K, Shimadzu M, Fukushima Y (1999) A new assay for the analysis of $\mathrm{X}$-chromosome inactivation based on methylation-specific PCR. Hum Genet 104:49-55

Lin MT, Chien YH, Shyur SD, Huang LH, Chiang YC, Wen DC, Liang PH, Yang HC (2006) De novo mutation in the BTK gene of atypical X-linked agammaglobulinemia in a patient with recurrent pyoderma. Ann Allergy Asthma Immunol 96:744-748

Lopez-Granados E, Perez de Diego R, Ferreira Cerdan A, Fontan Casariego G, Garcia Rodriguez MC (2005) A genotype-phenotype correlation study in a group of 54 patients with X-linked agammaglobulinemia. J Allergy Clin Immunol 116:690-697

Nakayama T, Watanabe M, Suzuki H, Toyota M, Sekita N, Hirokawa Y, Mizokami A, Ito H, Yatani R, Shiraishi T (2000) Epigenetic regulation of androgen receptor gene expression in human prostate cancers. Lab Invest 80:17891796

Ohta Y, Haire RN, Litman RT, Fu SM, Nelson RP, Kratz J, Kornfeld SJ, de la Morena M, Good RA, Litman GW (1994) Genomic organization and structure of Bruton agammaglobulinemia tyrosine kinase: localization of mutations associated with varied clinical presentations and course in X chromosome-linked agammaglobulinemia. Proc Natl Acad Sci USA 91:9062-9066

Perez de Diego R, Lopez Granados E, Ferreira Cerdan A, Fontan Casariego G, Garcia Rodriguez MC (2005) Kinase activity and XLA phenotypic variability. J Allergy Clin Immunol 115:205-206

Rodriguez MC, Granados EL, Cerdan AF, Casariego GF (2001) Molecular analysis of Bruton's tyrosine kinase gene in Spain. Hum Mutat 18:84 
Tzeng SR, Pai MT, Lung FD, Wu CW, Roller PP, Lei B, Wei CJ, Tu SC, Chen SH, Soong WJ, Cheng JW (2000) Stability and peptide binding specificity of Btk $\mathrm{SH} 2$ domain: molecular basis for X-linked agammaglobulinemia. Protein Sci 9:23772385

Velickovic M, Prasad ML, Weston SA, Benson EM (2004) Identification of the bruton tyrosine kinase (BTK) gene mutations in 20 Australian families with X-linked agammaglobulinemia (XLA). Hum Mutat 23:398-399

Vihinen M, Nilsson L, Smith CI (1994) Structural basis of SH2 domain mutations in X-linked agammaglobulinemia. Biochem Biophys Res Commun 205:1270-1277

Vorechovsky I, Vihinen M, de Saint Basile G, Honsova S, Hammarstrom L, Muller S, Nilsson L, Fischer A, Smith CI (1995) DNA-based mutation analysis of Bruton's tyrosine kinase gene in patients with $\mathrm{X}$-linked agammaglobulinaemia. Hum Mol Genet 4:51-58

Weinhausel A, Haas OA (2001) Evaluation of the fragile X (FRAXA) syndrome with methylation-sensitive PCR. Hum Genet 108:450-458

Yamazaki T, Katsumi A, Okamoto Y, Takafuta T, Tsuzuki S, Kagami K, Sugiura I, Kojima T, Fujimura K, Saito H (1997) Two distinct novel splice site mutations in a compound heterozygous patient with protein $\mathrm{S}$ deficiency. Thromb Haemost 77:14-20

Zenone T, Souillet G (1996) X-linked agammaglobulinemia presenting as Pseudomonas aeruginosa septicemia. Scand J Infect Dis 28:417-418 